\title{
Percutaneous Coronary Intervention in Left Main Coronary Artery Disease - A Case Report
}

\section{AHK CHOWDHURY, M SALEH UDDIN, MD. KHALEQUZZAMAN, AKM MONWARUL ISLAM, SHAWKAT ALI, UDOY SHANKAR ROY, MD. ABDUL QUAYYUM, MAMUNUR RASHID SHIKDER, MOHAMMAD NASIMUL GANI, SHAHANA ZAMAN, MAHBUBUR RAHMAN, SK. ZIARAT ISLAM}

Department of Cardiology, National Institute of Cardiovascular Diseases, Dhaka.

Address of Correspondance: Prof. AHK Chowdhury, Lab Aid Cardiac Hospital, Road No. 4, Dhanmondi Residential Area, Dhaka, Bangladesh, E-mail: chowdhuryfarid1@yahoo.com

Left main coronary artery (LMCA) atherosclerosis bears extra importance because of the large territory of myocardium supplied by the vessel. By convention, significant LMCA stenosis is treated by coronary artery bypass graft (CABG) surgery, and this type of lesion has long been regarded as a contraindication for percutaneous coronary intervention (PCI). However, with the advancement in interventional tools, operators' expertise, pharmaceuticals and supportive measures, outlook regarding left main PCI is changing. Recent clinical trials tell about the feasibility of LMCA PCI. The three cases of significant left main lesion presented here, were treated successfully by percutaneous transluminal coronary angioplasty (PTCA) with stenting in National Institute of Cardiovascular Diseases (NICVD), Dhaka. In near future, PCI may be an equally effective alternative to surgical revascularization in judiciously selected cases of LMCA stenosis even in Bangladesh.

\section{Case 1:}

Mr. AB, a 43-year-old smoker, who was hypertensive but non-diabetic, was admitted into NICVD, Dhaka. Two weeks back, he was treated as a case of unstable angina in Chittagong Medical College Hospital (CMCH). Coronary angiography (CAG) done in Chittagong Medical College Hospital (CMCH) revealed severe left main coronary artery
(LMCA) disease with 70-80\% stenosis at its mid part, for which he was referred to NICVD for further management. His resting ECG showed ST depression in lead II, III, AVF, $\mathrm{V}_{5}$ and $\mathrm{V}_{6}$; echocardiography disclosed septal and inferior left ventricular wall hypokinesia with left ventricular ejection fraction (LVEF) 54\%. Blood counts and biochemistry including sugar, creatinine and lipid profile were normal. Serological tests i.e. HBsAg, Anti-HCV, AntiHIV, VDRL were negative. PTCA and stenting to LMCA was done uneventfully. The LMCA lesion was negotiated with floppy PTCA guidewire, and a 3.0x10 mm cobultchromium stent was deployed at the lesion at $14 \mathrm{~atm}$ pressure, preceded by dilatation with a $1.5 \times 6 \mathrm{~mm}$ balloon at $8 \mathrm{~atm}$. TIMI III flow was established (Fig. 1). Postprocedural period was uneventful. An anesthesiologist was constantly present in the cath lab and a full coronary artery bypass graft (CABG) team was kept ready for emergency revascularization surgery, if needed.

\section{Case 2:}

Mr. AK, a 38-year-old normotensive, nondiabetic but dyslipidaemic man, with a strong family history of coronary artery disease, presented to NICVD with compressive chest pain. He was haemodynamically stable with pulse 80 beats per minute, blood pressure 120/75 $\mathrm{mm} \mathrm{Hg}$, lung bases were clear and heart sounds were

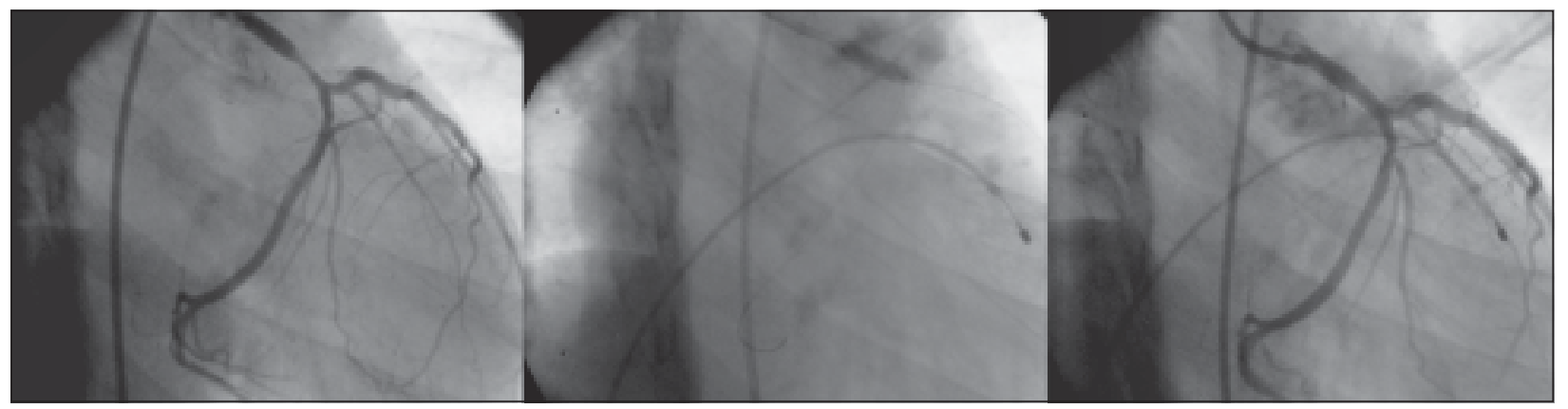

Fig. 1: Steps of PCI in LMCA of Mr. AB. 
normal. His ECG was within normal limits. CK-MB and troponin I were also normal. Echocardiography showed normal left ventricular (LV) wall motion and function. He was diagnosed as a case of unstable angina and treated accordingly with antiplatelets, beta-blockers, nitrate, atorvastatin and low-molecular-weight heparin. Coronary angiography revealed about $60 \%$ stenosis in the distal part of LMCA, and 75\% stenosis in the mid segment of right coronary artery (RCA). Subsequently, elective PTCA with stenting to LMCA and RCA lesion was done. Arrangements for emergency CABG surgery were ensured beforehand. The LMCA lesion was negotiated with floppy PTCA guidewire, and a 3.0x9 mm cobultchromium stent was deployed at the lesion at $14 \mathrm{~atm}$ pressure. Another 2.75x10 mm cobalt-chromium stent was deployed across the RCA lesion at 8 atm pressure, preceded by dilatation with a 2.5x10 mm balloon at 8 atm. TIMI III flow was established (Fig. 2). Post-procedural period was uneventful.

\section{Case 3:}

Mr. BK, a 55-year-old hypertensive, non-diabetic exsmoker, with no family history of coronary artery disease, presented to NICVD with history of acute inferior myocardial infarction 2 months back. His ECG showed pathological Q and inverted T waves in lead II, III and aVF. Echocardiography revealed inferior LV wall hypokinesia, with LVEF 50\%. CAG done elsewhere, revealed $75-80 \%$ stenosis in LMCA, and 70-75\% stenosis in the distal segment of RCA. Subsequently, elective PTCA with stenting to LMCA and RCA lesions was done ensuring arrangements for emergency CABG surgery. The LMCA lesion was negotiated with floppy PTCA guidewire, and a 3.5x10 mm drug-eluting stent was deployed at the lesion at 18 atm pressure. Another $2.5 \times 22 \mathrm{~mm}$ cobalt-chromium stent was deployed across the RCA lesion at 16 atm pressure. TIMI III flow was established (Fig. 3). Post-procedural period was uneventful.

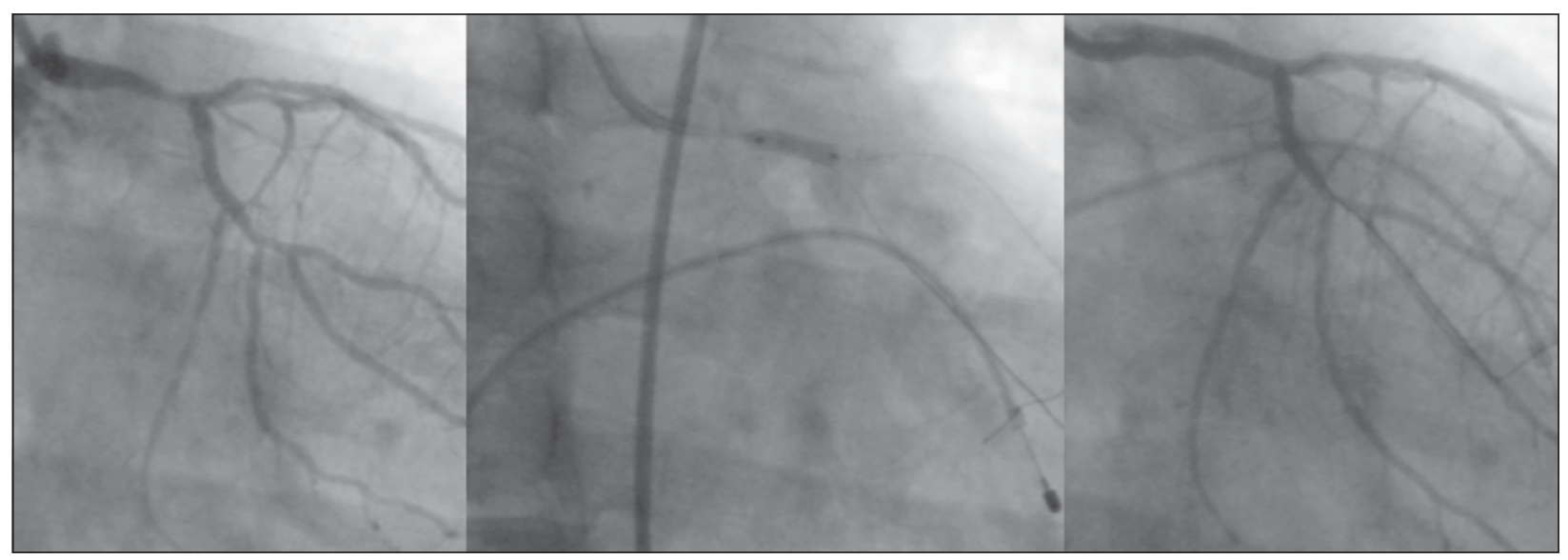

Fig. 2: Steps of PCI in LMCA of Mr. AK.

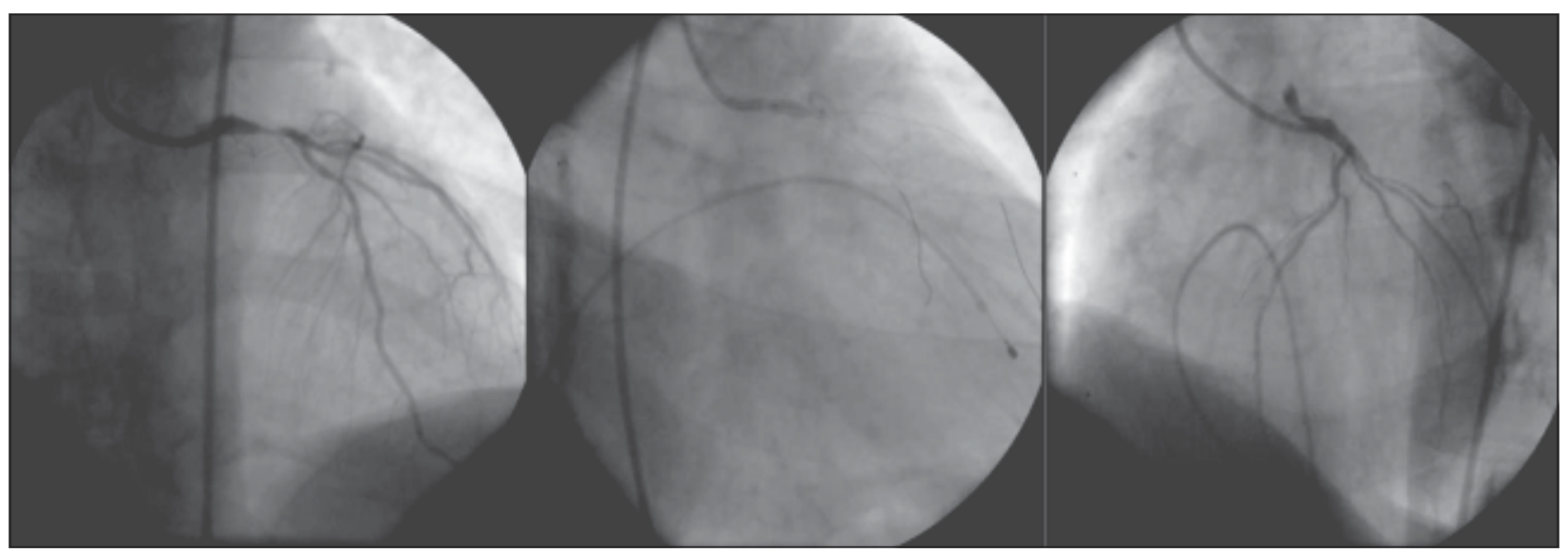

Fig. 3: Steps of PCI in LMCA of Mr. BK. 


\section{Discussion:}

Introduction and Epidemiology

The left main coronary artery atherosclerosis is a condition that merits special attention, because occlusion of LMCA is potentially fatal due to the large myocardial territory affected. ${ }^{1}$ The prevalence of LMCA stenosis in patients undergoing CAG ranges from 2.5 to $10 \%$, usually associated with lesions in other coronary branches. ${ }^{2,3}$ Isolated LMCA disease is very rare, only $0.07-0.15 \%$ in CAG patients. ${ }^{4-6}$ Patients with significant LMCA stenosis who are on medical treatment, have a poor prognosis; three-year survival rate ranges from $60-82 \%^{7,8}$, and $15-$ year survival rate was $27 \%{ }^{9}$.

\section{Peculiarity of LMCA Stenosis}

The diameter of normal human LM coronary artery is 4.5 \pm $0.5 \mathrm{~mm}$ in men and $3.9 \pm 0.4 \mathrm{~mm}$ in women. ${ }^{10}$ The LMCA directly originates from the ascending aorta, so all diseases of aorta affect the LM trunk. The LM trunk lacks adventitia and has greater amount of smooth muscle and elastic tissue which is probably responsible for the excellent 'acute success' of balloon dilatation but more chance of early and late recoil. ${ }^{11}$ Because of larger diameter, percutaneous coronary intervention (PCI) seems to be a suitable procedure for treating LMCA lesions. ${ }^{1}$ However, in case of restenosis, recurrence of angina is often accompanied by risk of developing acute left ventricular failure and sudden death. ${ }^{1}$

\section{Treatment Options for LMCA Stenosis}

Coronary artery bypass graft is still regarded as the treatment of choice for significant LMCA stenosis. PCI is conventionally a class III recommendation for the same purpose as per the guidelines published by the American Heart Association/ American College of Cardiology. ${ }^{12}$ However, with the introduction of coronary stents, several reports have demonstrated the feasibility of unprotected LMCA stenosis treatment by PCI. ${ }^{13}$ Subsequently, drugeluting stents (DESs) in conjunction with advances in periprocedural and postprocedural adjunctive pharmacotherapies, have improved the outcomes of PCI in LMCA lesion. ${ }^{14,15}$

\section{The Problems of PCI in LMCA Stenosis}

Gruntzig et al did the percutaneous transluminal coronary angioplasty (PTCA) of the unprotected LMCA stenosis for the first time, and reported that such procedures were quite difficult to perform and that early mortality was too high to be accepted as a standard treatment. ${ }^{16}$ Subsequent reports of PTCA to LMCA were also disappointing. ${ }^{17-21}$
LMCA stenosis was considered as a contraindication to PTCA in the consensus published by the Heart, Lung and Blood Institute (NIHL\&BI) in 1984. With the introduction of coronary stents, the outcomes of PCI in LMCA stenosis became more favourable. Silverstri et $\mathrm{al}^{22}$ in 140 and Wong et $\mathrm{al}^{23}$ in 50 elective PCI cases of unprotected LMCA stenosis found $100 \%$ procedural success, low short-term mortality and relative low restenosis rates (20-23\%). Use of DESs in LM PCI further reduced the incidence of angiographic restenosis and, subsequently, the need for repeat revascularization in unprotected LMCA stenosis. ${ }^{24-}$ ${ }^{26}$ The 1-year incidence of repeat revascularization in DES implantation was $2-10 \%$, as compared to $12-31 \%$ in bare metal stent (BMS) implantation. ${ }^{14,15,24,25,27}$

\section{PCI versus CABG in LMCA Stenosis}

Elective PCI in unprotected LMCA stenosis that can be treated by CABG, is a contraindication as per the current guidelines. ${ }^{28}$ In-stent restenosis after BMS implantation is the most important reason for bypass surgery being the first choice of treatment. ${ }^{29}$ However, this recommendation is based on the clinical trials that are more than 20 years old, so the results of these trials may not be optimally applicable to current practice. ${ }^{30}$ On the other hand, recent observational studies and randomized trials comparing PTCA with stenting to CABG in the management of LMCA lesion are more encouraging. ${ }^{24,27,31-38}$ Lee et al. ${ }^{26}$ and Chieffo et al. ${ }^{31}$ found better short-term outcomes in terms of death, myocardial infarction (MI) and target-vessel revascularization in PTCA with DES group. Death and MI after 6-12 months' observation were also less in DES implantation group, whereas restenosis rates were higher than that in CABG group. Palmerini et al found almost comparable results but MI and 14-month revascularization were less common in CABG group. ${ }^{24}$ In a more recent study involving a cohort of patients with unprotected left main coronary artery disease, Seung et $\mathrm{al}^{32}$ found no significant difference in rates of death or of the composite end point of death, Q-wave myocardial infarction, or stroke between patients receiving stents and those undergoing CABG, but stenting was associated with higher rates of target-vessel revascularization than was CABG. The nonrandomized MAIN-COMPARE (Revascularization for Unprotected Left Main Coronary Artery Stenosis: Comparison of Percutaneous Coronary Angioplasty versus Surgical Revascularization) trial involving 2,240 patients with UPLM disease compared outcomes according to treatment with percutaneous revascularization (DES 71\%/bare-metal stent 29\%) or CABG (43). During 5-year follow-up, stenting showed 
similar rates of mortality and In the randomized SYNTAX (Synergy Between Percutaneous Coronary Intervention With TAXUS and Cardiac Surgery) trial comparing CABG with PCI for left main/multivessel disease, patient treatment assignment was stratified according to the presence of significant UPLM disease, representing a patient cohort $(n=705)$ with approximately $60 \%$ bifurcation disease and $13 \%$ isolated left main disease (i.e., no additional target lesions) (8). For the overall left main subgroup, there were no differences in 1-year individual outcomes of death or myocardial infarction, despite significantly higher rates of stroke in the CABG group (2.7\% CABG vs. 0.3\% PCI, $\mathrm{p}=0.009)$. Repeat revascularization was more common with PCI (6.7\% CABG vs. 12.0\% PCI, p=0.02) and was particularly driven by higher rates among patients with left main disease treated for additional 2-vessel (15.3\% vs. $7.7 \%$, $\mathrm{p}=0.08$ ) or 3 -vessel (14.8\% vs. 6.0\%, $\mathrm{p}=0.02$ ) disease.

Drug-eluting Stent versus Bare-metal Stent in LMCA Stenosis

Angiographic and procedural successes do not differ significantly between DES and BMS in case of LMCA PCI. DES has been associated with reduced incidence of in-stent restenosis ${ }^{40}$ at the cost of increased risk of late stent thrombosis. DES use in unprotected LMCA revascularization represents a narrow margin between the need for a potent antirestenotic effect balanced by the risk of stent thrombosis related to delayed healing. ${ }^{41}$ Onuma et al. ${ }^{42}$ compared the long-term clinical outcomes in unprotected LMCA PCI using DES ( $n=148)$ with those using BMS ( $n=79)$. The 4-year cumulative incidence of allcause death, any myocardial infarction, any revascularization, and patient-oriented composite were $35.6 \%$, 3.8\%, 25.2\%, and 54.4\%, respectively. Over 2 years of follow-up, the DES cohort had significantly higher patient-oriented composite end point in comparison to the BMS cohort ( $26 \%$ vs. $8 \%$, p=0.02). However, recent multicenter registries evaluating the occurrence of late and very late stent thrombosis have shown the incidence of stent thrombosis to be 0.5 to $1.7 \%$, which is a relatively uncommon phenomenon. ${ }^{43,44}$ In a large population of patients with lesions located at the ostium or the shaft of the left main in a real-world setting, DES were associated with favourable clinical outcomes when compared with BMS, although there was no evidence of a significant reduction in TLR with DES vs. BMS. ${ }^{45}$ In a recently published meta-analysis DES has been found to be associated with favorable outcomes for mortality, myocardial infarction, target-vessel/lesion revascularization, and MACE as compared to BMS in unprotected LMCA PCI. ${ }^{46}$

\section{Conclusion:}

The exact incidence and prevalence of LMCA stenosis in Bangladesh are unknown. In this country, a good number of PCIs is being performed round the year in Government and private levels. Like elsewhere, LMCA lesions are treated mainly by CABG surgery. However, operator expertise, pharmacotherapeutics and auxiliary supports are developing in this country day by day. The three cases of LMCA stenosis treated by PTCA with stenting presented, advocates the feasibility of complex coronary intervention here. PTCA with stenting specially using DES will hopefully become a viable alternative to CABG in carefully selected patients with left main disease.

\section{References:}

1. Ochiai M. PCI of the unprotected left main trunk: technical consideration for LMT intervention. Cardiac Interventions Today. September 2007; 40-2.

2. Cohen MV, Cohn PF, Herman MV, Gorlin R. Diagnosis and prognosis of main left coronary artery obstruction. Circulation 1972; 45(Suppl 1): 57-65.

3. Proudfit WL, Shirey EK, Sones FM Jr. Distribution of arterial lesions demonstrated by selective cinecoronary arteriography. Circulation 1967; 36: 54-62.

4. Tommaso CL, Applefeld MM, Singleton RT. Isolated left main coronary artery stenosis and mediastinal radiotherapy as an etiologic factor. Am J Cardiol 1988; 61: 1119-20.

5. Miller GAH, Honey M, El-Sayed H. Isolated coronary ostial stenosis. Cath Cardiovasc Diagn 1986; 12: 30-4.

6. Topaz O, Warner M, Lanter P, Soffer A. Isolated significant left main coronary artery stenosis: angiographic, haemodynamic, and clinical findings in 16 patients. Am Heart J 1991; 122: 1308-14.

7. Chaitman BR, Fisher LD, Bourassa MG, Davis K, Rogers WJ, Maynard C, Tyras DH, Berger RL, Judkins MP, Ringqvist I, Mock MB, Killip T. Effect of coronary bypass surgery on survival patterns in subsets of patients with left main coronary artery disease - Report of the Collaborative Study in Coronary Artery Surgery (CASS). Am J Cardiol 1981; 48: 765-77.

8. European Coronary Surgery Study Group. Prospective randomized study of coronary artery bypass surgery in stable angina pectoris - Second interim report by the European Coronary Surgery Study Group. Lancet 1980; 2: 491-5.

9. Caracciolo EA, Kathryn BD, Sopko G, Kaiser GC, Scott DC, Schaff H, Taylor HA, Chaitman BR, for the CASS investigators. Comparison of surgical and medical group survival in patients with left main coronary artery disease. Circ 1995; 91: 2325-34.

10. Dodge JT Jr, Brown BG, Bolson EL, Dodge HT. Lumen diameter of normal human coronary arteries: influence of age, sex, anatomic variation, and left ventricular hypertrophy or dilation. Circulation 1992; 86: 232-46. 
11. Sperker W, Gyongyosi M, Glogar D. Percutaneous treatment of left main coronary artery stenoses. J Clin Basic Cardiol 2002; 5:163-9.

12. Smith SC Jr, Dove JT, Jacobs AK, et al. ACC/AHA guidelines for percutaneous coronary intervention (revision of the 1993 PTCA guidelines): executive summary. Circulation 2001; 103: 3019.

13. Park SJ, Mintz GS. Left main stem disease. Seoul: Informa Healthcare; 2006.

14. Montalescot G, Brieger D, Eagle KA, et al. for the GRACE Investigators. Unprotected left main revascularization in patients with acute coronary syndromes. Eur Heart J 2009;30:2308-17.

15. Price MJ, Cristea E, Sahney N, et al. Serial angiographic follow-up of sirolimus-eluting stents for unprotected left main coronary artery revascularization. J Am Coll Cardiol 2006; 47:871-7.

16. Gruntzig AR, Senning A, Siegenthaler WE. Nonoperative dilatation of coronary artery stenosis: Percutaneous transluminal coronary angioplasty. $N$ Engl J Med 1979; 301: $61-8$.

17. Stertzer SH, Myler RK, Insel H, Wallsh E, Rossi P. Percutaneous transluminal coronary angioplasty in left main stem coronary stenosis: a five-year appraisal. Int J Cardiol 1985; 9: 149-59.

18. O' Keefe JH, Hartzler GO, Rutherford, McConahay DR, Johnson WL, Giorgi LV, Ligon RW. Left main coronary angioplasty: early and late results of 127 acute and elective procedures. Am J Cardiol 1989; 64: 144-7.

19. Ellis SG, Tamai H, Masakiyo N, Kunihiko K, Colombo A, Holmes DR, Macaya C, Grines CL, Whitlow PL, Whitie HJ, Moses J, Teierstein PS, Serruys PW, Bittl JA, Mooney MR, Shimshak TM, Block PC, Erbel R. Contemporary percutaneous treatment of unprotected left main coronary stenoses. Circulation 1997; 96: 3867-72.

20. Rupprecht HJ, Oelert H, Trautmann S, Pop T, Iversen S, Erbel R, Meyer J. PTCA of the left main stem following protective coronary artery bypass grafting. Eur J Cardiothorac Surg 1991; 5: 326-9.

21. Eldar M, Schulhoff N, Herz I, Frankel R, Feld H, Shani J. Results of percutaneous transluminal angioplasty of the left main coronary artery. Am J Cardiol 1991; 68: 255-6.

22. Silvestri M, Barragan P, Sainsous J, Bayet G, Simeoni JB, Roquebert PO, Macaluso G, Bouvier JL, Comet B. Unprotected left main coronary artery stenting: immediate and mediumterm outcomes of 140 elective procedures. J Am Coll Cardiol 2000; 35: 1543-50.

23. Wong P, Wong V, Tse KK, Chan W, Ko P, Wong CM, Leung AW, Fong PC, Cheng CH, Tai YT, Leung WH, Liu ML. A prospective study of elective stenting in unprotected left main coronary disease. Catheter Cardiovasc Interv 1999; 46: 153-9.

24. Park SJ, Kim YH, Lee BK. et al. Sirolimus-eluting stent implantation for unprotected left main coronary artery stenosis: comparison with bare metal stent implantation. $J$ Am Coll Cardiol 2005; 45: 351-6.
25. Chieffo A, Stakovic G, Bonizzoni E, et al. Early and mid-term results of drug-eluting stent implantation in unprotected left main. Circulation 2005; 111: 791-5.

26. Lee SH, Ko YG, Jang Y, et al. Sirolimus- versus paclitaxeleluting stent implantation for unprotected left main coronary artery stenosis. Cardiology 2005;104:181-5.

27. Valgimigli M, van Mieghem CA, Ong AT, et al. Short- and long-term clinical outcome after drug-eluting stent implantation for the percutaneous treatment of left main coronary artery disease: insights from the Rapamycin-Eluting and Taxus Stent Evaluated At Rotterdam Cardiology Hospital registries (RESEARCH and T-SEARCH). Circulation 2005; 111: 1383-9.

28. Smith SC Jr, Feldman H, Hirshfeld JW Jr, et al. ACC/AHA/ SCAI 2005 guideline update for percutaneous coronary intervention: a report of the American College of Cardiology/ American Heart Association Task Force on Practice Guidelines (ACC/AHA/SCAI Writing Committee to Update 2001 Guideline for Percutaneous Coronary Intervention). Circulation 2006; 113:e166-286.

29. Chikwe J, Kim M, Goldstone AB et al. Current diagnosis and management of left main coronary disease. Eur J Cardiothorac Surg 2010;38:420-30.

30. Park SJ, Kim YK. Left main coronary disease. Current evidence for drug-eluting stent placement in unprotected left main coronary disease. Cardiac Interventions Today. September 2007; 47-51.

31. Chieffo A, Morici N, Maisano F, et al. Percutaneous treatment with drug-eluting stent implantation versus bypass surgery for unprotected left main stenosis: a single-centre experience. Circulation 2006; 113: 2542-7.

32. Seung KB, Park DW, Kim YH, et al. Stents versus coronary artery bypass grafting for left main coronary artery disease. N Engl J Med 2008;358:1781-92.

33. Taggart DP, Kaul S, Boden WE, et al. Revascularization for unprotected left main stent coronary artery stenosis. Stenting or surgery. J Am Coll Cardiol 2008;51:885-92.

34. Smith CR. Surgery, not percutaneous revascularization, is the preferred strategy for patients with significant left main coronary stenosis. Circulation 2009;119:1013-20.

35. Teirstein PS. Percutaneous revascularization is the preferred strategy for patients with significant left main coronary stenosis. Circulation 2009;119:1021-33.

36. Chieffo A, Park SJ, Valgimigli M, et al. Favorable long-term outcome after drug-eluting stent implantation in nonbifurcation lesions that involve unprotected left main coronary artery: a multicenter registry. Circulation 2007;116:158-62.

37. Park DW, Seung KB, Kim YH et al. long-term safety and efficacy of stenting versus coronary artery bypass grafting for unprotected left main coronary artery disease. 5-year results from the MAINCOMPARE (Revascularization for Unprotected Left Main Coronary Artery Stenosis: Comparison of Percutaneous Coronary Angioplasty versus Surgical Revascularization) Registry. J Am Coll Cardiol 2010;56:117-24. 
38. Morice MC, Serruys PW, Kappetein AP et al. outcomes in patients with de novo left main disease treated with either percutaneous coronary intervention using Paclitaxel-eluting stents or coronary artery bypass graft treatment in the Synergy Between Percutaneous Coronary Intervention With TAXUS and Cardiac Surgery (SYNTAX) trial. Circulation 2010;121:2645-53.

39. Boudriot E, Thiele H, Walther T, Liebetrau C, Boekstregers P, Pohl T, Reichart B, Mudra H, Beier F, Gansera B, Neumann FJ, Gick M, Zietak E, Desch S, Schuler G, Mohr FW. Randomized comparison of percutaneous coronary intervention with sirolimus-eluting stents versus coronary artery bypass grafting in unprotected left main stenosis. J Am Coll Cardiol 2011;57:538-45.

40. Erglis A, Narbute I, Kumsars I, et al. A randomized comparison of paclitaxel-eluting stents versus bare-metal stents for treatment of unprotected left main coronary artery stenosis. J Am Coll Cardiol 2007;50:491-7.

41. Kandzari DE, Colombo A, Park SJ et al. on behalf of the American College of Cardiology Interventional Scientific Council. Revascularization for unprotected left main disease: Evolution of the evidence basis to redefine treatment standards. J Am Coll Cardiol 2009;54(17):1576-88.
42. Onuma Y, Girasis C, Nicolo Piazza N et al. Long-term clinical results following stenting of the left main stem: Insights from RESEARCH (Rapamycin-Eluting Stent Evaluated at Rotterdam Cardiology Hospital) and T-SEARCH (Taxus-Stent Evaluated at Rotterdam Cardiology Hospital) Registries. J Am Coll Cardiol Intv 2010;3:584-94.

43. Meliga E, Garcia-Garcia HM, Valgimigli M, et al. Longest available clinical outcomes after drug-eluting stent implantation for unprotected left main coronary artery disease: the DELFT (Drug Eluting stent for LeFT main) registry. J Am Coll Cardiol 2008;51:2212-9.

44. Chieffo A, Park SJ, Meliga E, et al. Late and very late stent thrombosis following drug-eluting stent implantation in unprotected left main coronary artery stenosis in a large multicentre registry. Eur Heart J 2008;29:2108 -15.

45. Tamburino C, Salvo MED, Capodanno D et al. Are drugeluting stents superior to bare-metal stents in patients with unprotected nonbifurcational left main disease? Insights from a multicentre registry Eur Heart J 2009;30:1171-9.

46. Pandya SB, Kim YH, Meyers SN et al. Drug-eluting versus bare-metal stents in unprotected left main coronary artery disease: A meta-analysis. J Am Coll Cardiol Intv 2010; 3: 602-11. 